\title{
Landing China Typhoon Extreme Analysis and Catastrophe Risk Management Research
}

\author{
Kaicheng Xing ${ }^{1,2} \quad$ Yuanyuan Jing ${ }^{1,2^{*}}$ Guihong $\mathrm{Ma}^{3}$ \\ 1. Key Laboratory of Meteorological and Ecological Environment of Hebei Province \\ 2. Hebei Climate Center \\ 3.Meteorological Bureau of Gaoyi County \\ Shijiazhuang, China \\ yuan_yuan_jing@sina.com \\ 登陆中国台风极端性分析与巨灾风险管理研究 \\ 邢开成 1,2 井元元 ${ }^{1,2 *}$ 马贵宏 ${ }^{3}$ \\ 1.河北省气象与生态环境重点实验室 \\ 2.河北省气候中心 \\ 3. 河北省石家庄市高邑县气象局 \\ 石家庄 050021, 中国 \\ yuan_yuan_jing@sina.com
}

\begin{abstract}
This paper analyzes the impact of typhoon and direct economic losses on coastal areas of China. In combination with the current situation of typhoon catastrophe management, and the typhoon catastrophe insurance burden on typhoon losses, there is a huge gap compared with international social insurance claims. The role of the insurance industry in dealing with catastrophe has not been fully realized. According to the trend that the risk of typhoon disasters landing in China may increase in the future, it is proposed that catastrophe risk management should be strengthened from the state. Establish effective typhoon catastrophe insurance laws and regulations and risk management guarantee system. The government strongly supports typhoon disaster insurance and reinsurance, and actively promotes the optimization of typhoon catastrophe insurance market system and catastrophe weather index insurance product innovation to spread typhoon catastrophe risk. To ensure the stability and unity of the post-disaster society and the stable development of the economy.
\end{abstract}

Keywords- typhoon, disaster, risk, management

摘要一本文分析全球变暖气候变化背景下, 中国沿海地区 受登陆台风影响和直接经济损失情况。结合目前台风巨灾管理 面临的形势, 以及台风巨灾保险对台风损失的承担率与国际社 会保险赔款相比存在巨大差距, 保险业在应对巨灾中的作用尚 未充分发挥等现实, 根据未来登陆中国台风灾害风险可能增大 的趋势, 提出应从国家高度强化巨灾风险管理, 结合我国实际
构建有效的台风巨灾保险法律法规和风险管理保障制度体系， 大力扶持台风灾害保险和再保险, 积极推动台风巨灾保险市场 体制机制优化和气象指数保险产品创新等巨灾管理对策, 以分 散台风巨灾风险, 保障灾后社会的安定团结和经济的稳定发 展。

关键词一台风, 灾害, 风险, 管理

\section{I . 引言}

在全球气候变化背景下, 极端气候事件频发, 导致 气象灾害风险进一步加剧。中国海岸线漫长, 是气候变 化敏感且受台风影响最多的国家之一, 登陆台风影响的 我国中东部沿海地区城市化及社会经济快速发展, 人口 与社会财富聚集程度位居全球前列, 台风频繁登陆对农 业、人口、房屋与经济社会生态构成重大威胁 ${ }^{[1]}$ 。台风 引起的直接灾害通常有三方面：一是狂风。台风风速大 都超过 17 米/秒, 甚至在 60 米/秒以上, 狂风巨浪能对海 上作业人员及设施, 陆上建筑、桥梁、车辆、树木等造 成破坏; 二是暴雨。台风降雨中心二天可降 100-300 毫 米，甚至 500-800 毫米暴雨，危险性、破坏性极大; 三 是风暴潮。近岸台风的强风和低气压作用使潮位猛涨, 如与天文大潮高潮位叠加, 能使潮位上升数米, 造成巨 大财产损失甚至人员伤亡; 另外台风极易诱发城市内涝、 房屋倒塌、山洪、泥石流等次生灾害。

巨灾是指对人民生命财产造成特别巨大的破坏损 失, 对区域或国家经济社会产生严重影响的自然灾害事 件。台风可引起海啸、大风、洪水、特大风暴潮等灾害, 是影响我国东南部沿海频次最高、灾害损失最重的自然 
巨灾。其损失程度不仅取决于台风强度、登录时间, 还 取决于受灾地区的人口密度、建筑规模和标准、该地区 的防灾减损能力情况等 ${ }^{[2]}$ 。我国自然灾害频发, 强化巨 灾风险管理是促进我国社会治理体系现代化的重要举 措, 搭建政府、科研机构、保险公司等多方参与的跨学 科、跨领域的合作平台, 加强巨灾风险应对与分散机制 顶层设计, 制定巨灾风险管理科学解决方案, 形成“数据 +技术 + 服务”的核心竞争力, 提升巨灾风险模型构建、数 据库建设等巨灾风险防御技术与管理创新工作水平, 将 巨灾防御技术与巨灾风险管理更深融入到国家防灾减灾 体系之中, 建设完善巨灾风险管理体系, 为保障民生、 服务实体经济、服务人类共同体贡献力量。

2014 年国务院发布《关于加快发展现代保险服务业 的若干意见》（国发（2014）29 号）明确提出“建立巨 灾保险制度”、“研究建立巨灾保险基金、巨灾再保险等 制度，逐步形成财政支持下的多层次巨灾风险分散机 制”、“建立巨灾风险管理数据库”。十九大报告也明确提 出要“健全公共安全体系, 提升防灾减灾救灾能力”。气 候变化导致登陆我国台风灾害造成的经济损失呈增长趋 势, 加强对登陆台风影响规律研究, 强化台风灾害风险 管理是防灾减灾、保障民生的需要, 也是促进经济社会 可持续发展和生态文明建设的基础性工作, 从国家高度 加强台风巨灾风险管理, 构建有效的巨灾保险机制, 是 国家社会保障体系的重要组成部分, 是新时期有中国特 色社会主义现代化建设不能回避而且亟待解决的重要课 题, 也是巨灾保险制度建立和发展的根本保障（以下台 风数据来源于中国气象局中国热带气旋灾害数据集、国 家减灾中心灾害信息部和中国科学院减灾中心工作相关 项目，经济社会数据来源于相关权威部门网站）。

\section{II. 登陆中国台风极端性及影响分析}

中国拥有 1 万 8 千多千米海岸线, 蓝色国土面积 300 多万平方千米, 纵跨温、热两带, 渤海、黄海沿岸春、 秋季节易受温带风暴潮影响, 而东南沿海地区夏、秋季 节极易遭受台风灾害。登陆中国台风直接影响的我国中 东部地区经济发达、人口稠密, 广东、福建、浙江、上 海、海南、江苏、香港、澳门、湖南、安徽、广西、江 西、辽宁、台湾、山东、河北、北京、天津 18 个一级行 政区都不同程度受登陆台风的影响。改革开放 40 年来, 东部地区尤其是沿海省份经济持续快速发展, 城市化进 程不断加速, 2019 年中国城市发展潜力 50 强中有 38 座 城市在此区域之内。最新人口数据统计显示, 2019 年上 述省份人口总计 83967 万, 占全国人口的比例超过 $60 \%$; 不到 20\%的国土面积里高速公路总里程占到全国 30\%以 上, 高铁里程占到全国近 $70 \%, 2018$ 年拥有全国近 $80 \%$ 的 GDP。
1949 年以来, 西北太平洋 (含南海) 上平均每年生 成约 27 个台风, 平均每年有约 7 个台风登陆我国。其中 1967 年生成台风最多, 共生成 40 个台风（登陆我国 11 个)，1971 年登陆我国台风最多达 12 个(当年生成 37 个)。1-12 月均有台风生成, 其中 8 月、9 月生成台风最 多; 4-12 月均有台风登陆, 其中 7-9 月登陆台最多, 8 月 9 月的台风平均登陆端度最强, 均在 $34 \mathrm{~m} / \mathrm{s}$ 以上（图 1-图 5)。

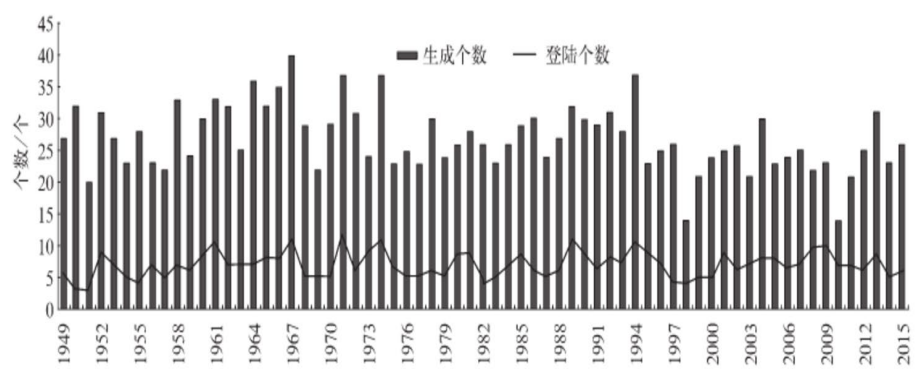

图 1.1949 年以来西太平洋生成及登陆中国台风逐年统计 情况

1949 年以来共有 9 个台风的登陆强度超过 $60 \mathrm{~m} / \mathrm{s}$, 4 个发生在 8 月, 3 个发生在 9 月, 2 个在 7 月。登陆强度 最大的是编号为 195914 号台风“Joan”, 在我国台湾登陆 时强度为 $75 \mathrm{~m} / \mathrm{s}$; 在我国大陆登陆强度超过 $60 \mathrm{~m} / \mathrm{s}$ 的台 风有 4 个, 分别是 201409 号在海南登陆的台风“威马逊”, 200610 号在浙江登陆的台风“桑美”。197317 在海南登陆 的台风“Marge”, 以及 195612 号在浙江登陆的台风 “Wanda”1949 年以来, 西北太平洋(含南海)上平均每年 生成约 $75 \mathrm{~m} / \mathrm{s}$ 。1949 年以来, 共有 17 个台风以超强台风 的级别在我国东部和南部沿海登陆, 超强台风登陆最多 的地区是台湾, 其次是浙江和海南。17 个超强台风登陆 时间集中在 7-9 月, 有 9 个登陆时中心附近最大风力达 到 17 级或以上。

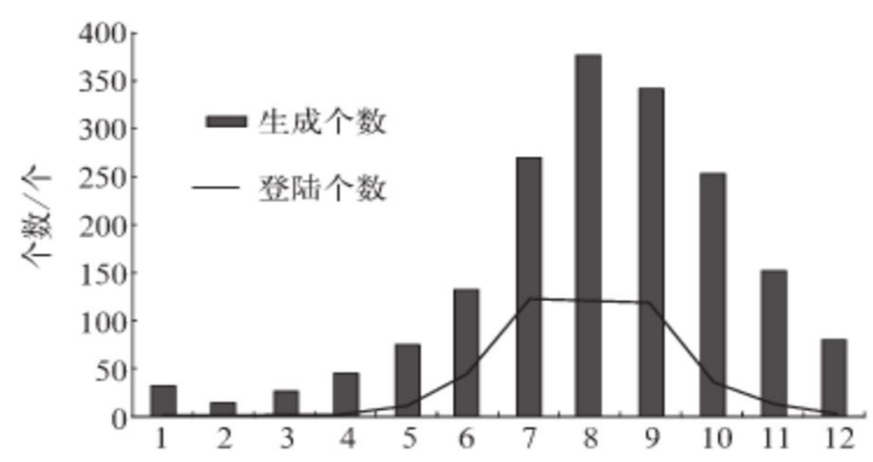

图 2.1949 年以来西太平洋生成及登陆中国台风逐月统计 情况 


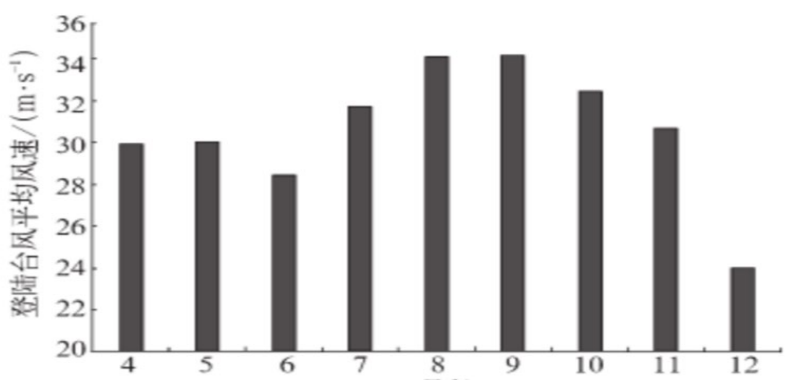

图 3.1949 年以来登陆中国台风强度逐月平均数量统计情 况

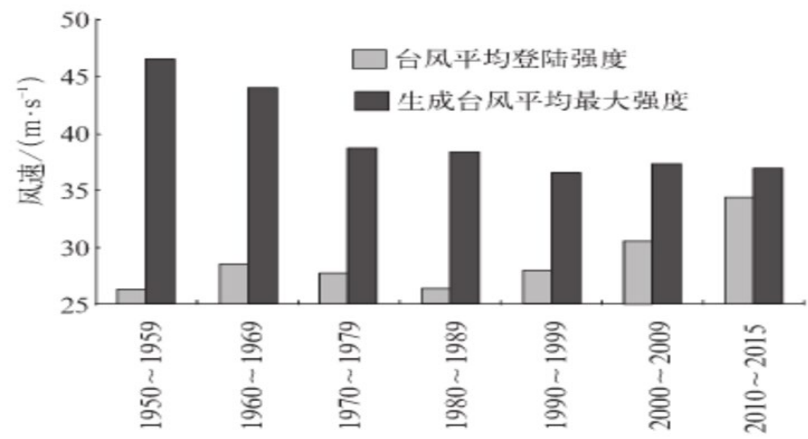

图 4.1949 年以来台风平均强度和平均最大风速逐年统计

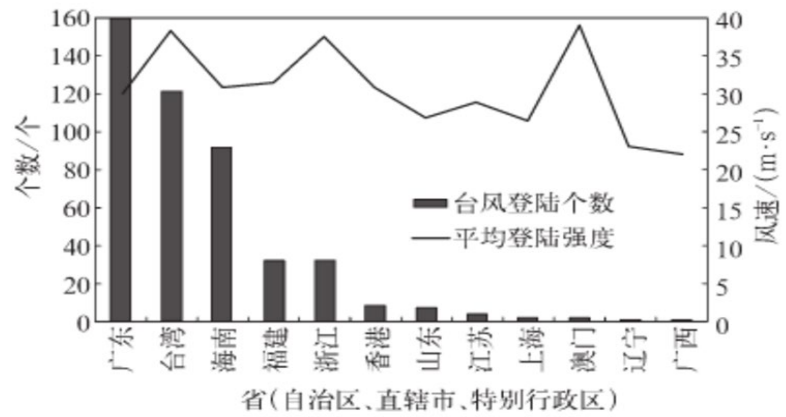

图 5.1949 年以来登陆中国台风个数及平均登陆强度统计

2012 年国际发展援助研究协会(DARA)发布《气候 脆弱性监测》 (The Climate Vulnerability Monitor)报告 称, 如今世界气候变化每年已经夺去近 40 万人的生命, 全球变暖的经济影响也已经造成每年超过 1.2 万亿美元 的损失，相当于全球 GDP 的 1.6\%。至 2030 年，气候 的改变会令全球 GDP 损失从 $1.6 \%$ 上升到 $3.2 \%$, 气候 变化正在对人类社会和经济发展造成前所未有的危害。

经济实体越发达, 台风灾害造成的经济损失就越大。 相对于经济欠发达地区呈现的基础设施相对落后和经济 实力不强, 沿海发达地区受到自然灾害将遭受更巨大的 经济损失, 包括直接经济损失和间接经济损失。气候变 暖导致的海平面上升, 沿海地区受台风灾害影响的风险 形势愈加严峻, 生态环境愈加脆弱, 带来一系列自然灾 害、事故灾害和公共事件以及经济、金融和社会安全风
险, 对沿海地区人民生命财产安全和社会经济发展造成 严重威胁。东南部沿海地区台风灾害的发生频率高, 受灾 人数多,直接经济损失十分严重, 而且灾害危险性及受灾 程度南方显著高于北部海岸。国家“一带一路”战略的实 施, 对沿海地区台风灾害风险管理水平提出了更高要求。

中国海洋灾害公报灾情统计显示：据 1949-2015 年 历史调查数据统计, 中国风暴潮灾害整体呈北部沿海地 区较弱、东南沿海地区显著较强的格局。尤以福建、广 东 2 省风暴潮发生累计频次最多,近几年登陆较为频繁; 山东、浙江、福建、广东、海南遭受风暴潮灾害的人员 伤亡较为严重, 其中浙江遭受风暴潮灾害的累计伤亡人 数高达 1962 人, 浙江、福建、广东 3 省的年平均直接经 济损失达 37 47 亿元。2005-2015 年中国风暴潮过程累计 200 多次,直接经济损失高达 1500 多亿元; 其中, 单次直接 经济损失超过 10 亿元的风暴潮灾害多达 34 次,直接经济 损失总计 1370 多亿元,约占所有风暴潮灾害总损失的 90\%; 而“1409 威马逊”“1319 天兔”“0814 黑格比”及“0518 达维”等特大风暴潮灾害则是由于风暴增水适逢天文大 潮或与近岸浪的共同影响, 单次直接经济损失约为 80-120 亿元（图 6-图 9) [3]。

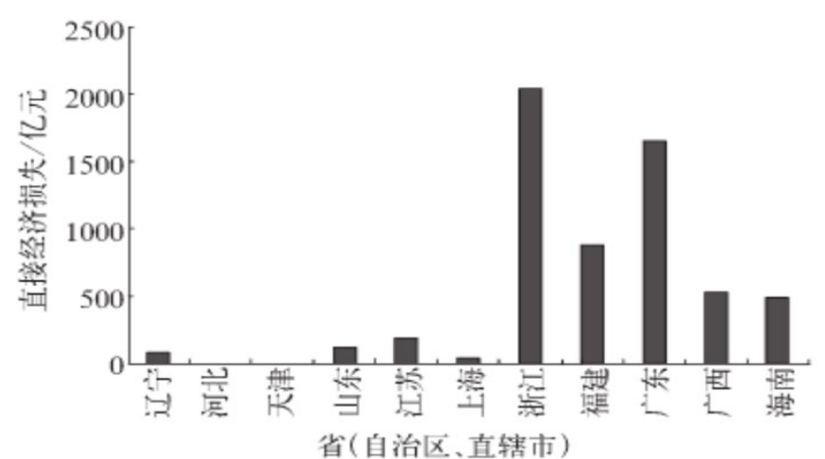

图 6. 2001 年以来沿海省份受台风影响直接经济损失情况

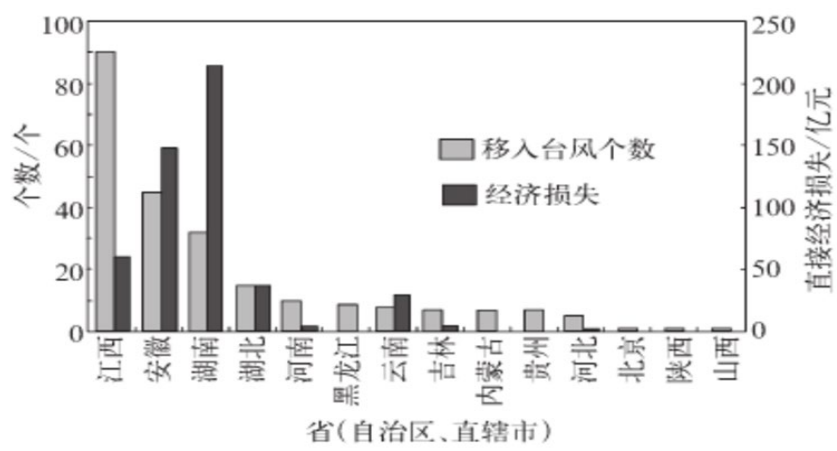

图 7.1949 年以来内陆省份移入台风个数及 2001 年以来 台风直接经济损失情况 


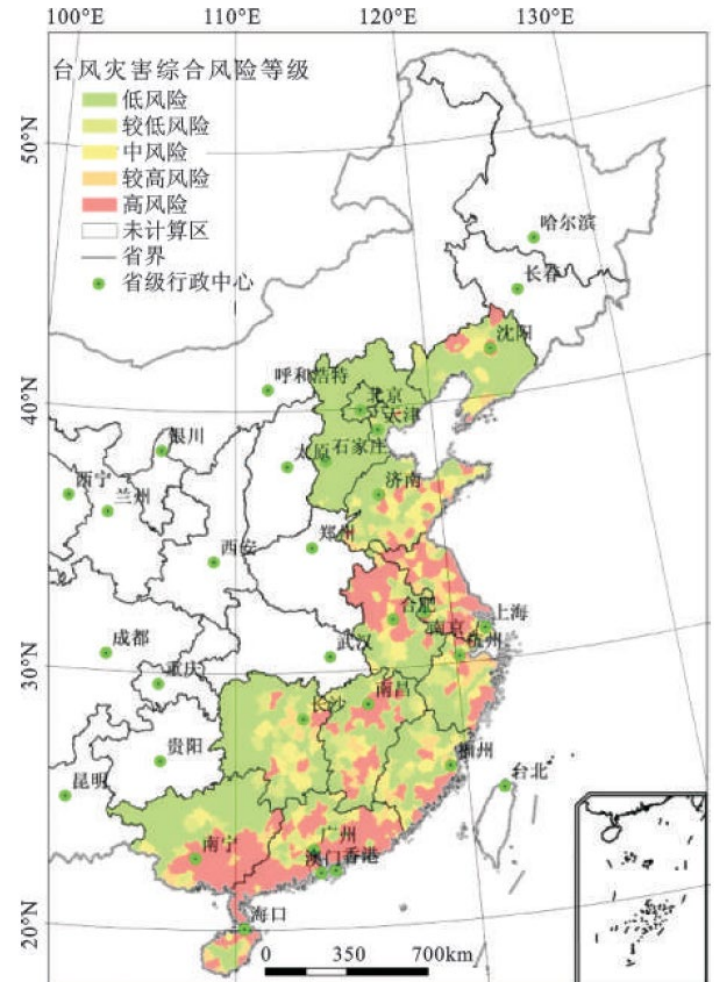

图 8. 中国台风灾害综合风险等级区划

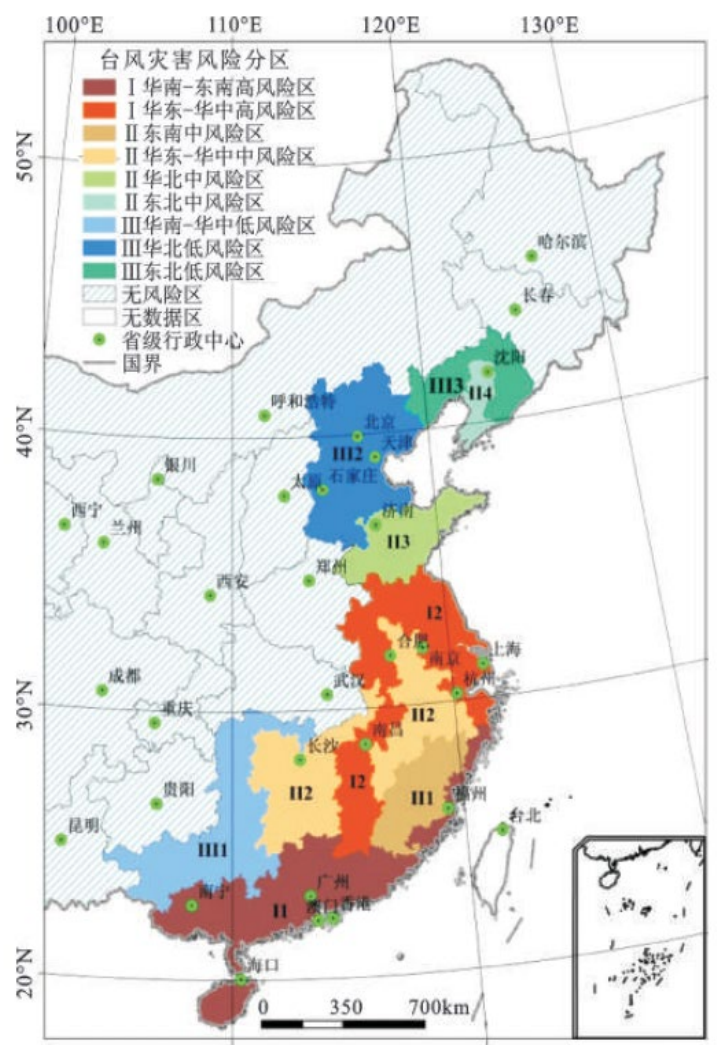

图 9. 中国台风灾害风险分区

\section{III. 台风巨灾管理面临的新形势}

观测事实表明, 西北太平洋和南海近 60 年来生成的 台风数呈下降趋势, 但登陆中国的台风强度明显增加。 21 世纪以来登陆台风中有一半最大风力超过 12 级, 比 上世纪 90 年代增加了 $46 \%$, 登陆时平均最大风速较 1981 年一 2000 年增大 $20 \%$ 。气候变化导致地表水变暖增强了 台风的能量, 热带气旋在过去 30 年总体有显著增强的趋 势, 这种趋势与热带气旋发生发展区域的海温升高趋势 相吻合 ${ }^{[4]}$ 。全球热带海温升高可以从理论上说明强热带 气旋增加的物理机制, 数值动力模型显示, 在全球变暖 气候背景下, 强热带气旋发生频率有增加的趋势, 热带 气旋的最大风速平均增加 $6 \%$, 移动速度则减慢 $9 \%$, 平 均每小时最高降雨量增加 $24 \%$, 台风巨灾风险还伴随着 社会发展而变大, 气候变化对于台风的影响将对公共安 全和经济发展产生重大影响（美国国家科学基金会大气 与地球空间科学部的项目主任埃德·本斯曼)。气候变暖 使台风变得越来越强, 造成的经济损失不断攀升, 未来 五十年, 这些负面影响很可能持续下去, 全球防灾减灾 和应对气候变化事业任重道远。（世界气象组织秘书长 佩蒂瑞·塔拉斯, 2018）。按照目前科学研究以及政府间 气候变化专门委员会 (IPCC) 第五次评估报告的分析, 全球气候变暖可能使得西北太平洋地区强台风的频次和 强度有一定程度的增加。

目前, 国内台风灾害损失主要是依靠政府救助, 保 险对台风损失的承担率还不到 $5 \%$, 跟国际社会保险赔款 在巨灾损失补偿中占 $30 \%-40 \%$ 的比例相比, 中国巨灾保 障的补偿作用不够明显, 我国保险业在应对巨灾中的作 用尚未充分发挥 ${ }^{[5]}$ 。结合国际气象学界关于极端性天气 气候事件发展趋势的最新研究结果, 根据未来登陆中国 沿海台风灾害风险可能增大的趋势, 强化登陆中国台风 巨灾风险管理, 优化巨灾保险策略, 不仅是社会民生问 题, 也为经济问题, 更是社会稳定和长治久安的政治问 题。

\section{IV. 加快巨灾保险制度建设}

完善极端天气气候事件“政府领导、部门联动、社会 参与”风险管理和灾害防御机制, 加强法律法规建设和应 急预案编制与执行, 依靠科技进步提高台风灾害预报预 警精度, 重视气候评价和灾害风险评估, 提升工程性防 御措施标准的同时, 提高巨灾保险制度建设水平和保障 能力, 是台风巨灾管理的重要战略选择。

1、充分认识利用保险机制防御和分散巨灾风险, 并提供灾后损失补偿的制度是市场经济条件下风险管理 体系的重要组成部分。2006 年 6 月《国务院关于保险业 改革发展的若干意见》提出, 要“建立国家财政支持的巨 
灾风险保险体系”，《国家综合减灾“十一五”规划》提到 “要加强巨灾综合应对能力建设, 建立健全应对巨灾风险 的体制、机制和政策措施，探索建立适合我国国情的巨 灾保险和再保险体系” [6]。这些制度性安排为台风巨灾保 险提供了法律制度保障。

2、从属性上分析，台风巨灾保险属于准公共物 品; 从体系范畴看, 台风巨灾保险属于政策保险; 从实 施方式看, 台风巨灾保险属于强制保险。台风巨灾保险 做为重要的风险管理手段, 对于灾后补偿、稳定社会、 保持经济正常发展具有重大意义。国外巨灾后保险赔付 可承担 $30 \%$ 以上损失补偿, 发达国家甚至可达 $60 \%$ 以上。 但我国的巨灾保险呈现“高风险、高损失、高赔付、低保 额、低保费、低保障”的“三高三低”特质, 中国人保近年 来支付的洪灾赔付金与灾害造成的经济损失之比是 1:100, 反映了现有巨灾保险市场本身巨大的风险。台风 巨灾保险不适用保险领域传统的“大数法则”和“可保性 原则”, 需要体现国家主导性和社会效益优先以及技术规 范性。

3、台风巨灾指数保险对推动和完善巨灾保险制 度具有重要意义, 能充分体现中央和地方政府运用现代 商业保险机制创新风险管理、保障和改善民生的先进意 识 ${ }^{[7]}$ 。气象部门相关业务单位完善精细化灾害风险数据 库及阈值集、山洪及中小河流洪水灾害风险评估预警系 统、城市内涝风险预警系统等, 做好台风巨灾风险的分 析、评估和预测的同时, 综合应用气象学、统计学、灾 害学、地理学、工程学、金融学等多学科知识, 为台风 巨灾保险方案和巨灾指数保险设计的确定提供基础资 料、技术支持和论证意见，采用气象指数保险作为巨灾 保险制度的运行模式, 因地制宜设计成灾指数, 确定触 发赔付阈值, 能节约实地查勘定损成本, 提高赔付效率 和整体抗风险能力。

综上所述，完善巨灾保险工作法律法规和制度系统， 建立长效的财政投入机制，建立专业的技术团队，设计 科学、合理、适用的巨灾气象指数保险产品和测算模型, 建设融灾害监测、风险预警、指数计算和理赔服务于一 体的巨灾风险管理业务平台，只有综合运用法律、制度、 技术规范、气象科技、巨灾保险和再保险等措施和手段， 才能发挥巨灾保险管理和分散巨灾风险的作用，为各地 政府及时了解巨灾事件发生发展状况、保险公司主动开 展保险理赔及防灾救灾提供科学有效的支撑。
2018YFA0606302）资助。

$$
\text { 参考文献 }
$$

[1] 秦大河. 中国极端天气气候事件和灾害风险管理与适应国家评估 报告. 2015

[2] [美]保罗・布莱肯, 等.突发事件战略管理: 风险管理与风险评估[M. ] 北京: 中央编译出版社, 2014.2 .

[3] 康斌.我国台风灾害统计分析,研究探讨, 2016.04.第 26 卷.第二期.

[4] 黄崇福,郭君,艾福利,等. 洪涝灾害风险分析的基本范式及其应用. 自然灾害学报,2013,(4):13-25.

[5] Huang C, Shi X.A Discrete Model of the Expected Loss for Catastrophe Insurance in Natural Disasters.Journal of Risk Analysis and Crisis Response, 2011,1(1): :48-58

[6] 王炜, 权循刚, 魏华. 从气象灾害防御到气象灾害风险管理的管理 方法转变,气象与环境学报,2011,27(1):7-13.

[7] 陈琳, 陈金金, 陆鹏程, 等. 农业气象保险在防御农业气象灾害中的作 用,现代农业科技,2016,7: 231-232。 